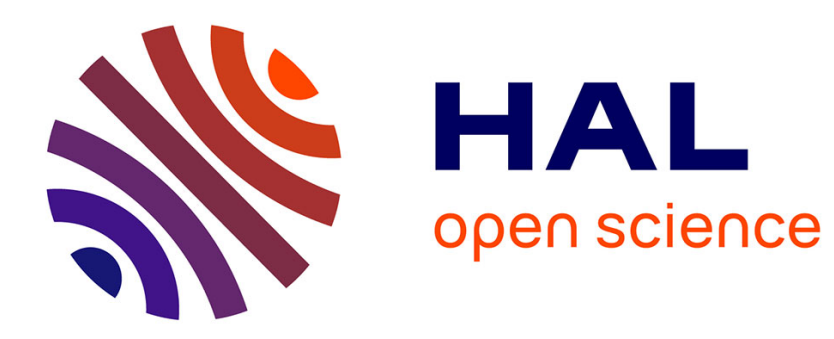

\title{
UN NOUVEAU DISPOSITIF POUR LA PRODUCTION DU LAIT CRU
}

\author{
J.-E. Lucas
}

\section{To cite this version:}

J.-E. Lucas. UN NOUVEAU DISPOSITIF POUR LA PRODUCTION DU LAIT CRU. Le Lait, 1923, 3 (7_8), pp.566-567. hal-00894741

\section{HAL Id: hal-00894741}

\section{https://hal.science/hal-00894741}

Submitted on 1 Jan 1923

HAL is a multi-disciplinary open access archive for the deposit and dissemination of scientific research documents, whether they are published or not. The documents may come from teaching and research institutions in France or abroad, or from public or private research centers.
L'archive ouverte pluridisciplinaire HAL, est destinée au dépôt et à la diffusion de documents scientifiques de niveau recherche, publiés ou non, émanant des établissements d'enseignement et de recherche français ou étrangers, des laboratoires publics ou privés. 
jamais un lait étranger ne peut se trouver au Vaan) : ceci donne encore une grande garantie de la bonne qualité du lait, car le veau est très sensible à l'infection par le lait eontenant des bacilles de Koch.

(A suive).

\section{UN NOUVEAU DISPOSITIF \\ POUR LA PRODUGTION DU LAIT GRU,}

par J.-E, LUCAS,

Ingénieur-Agronome.

Les études sur le lait ont montré que le meilleur lait, à mettre en vente pour malades et enfants, était encore le lait tei qu'il sort du pis de la vache, sans lui faire subir aucune manipulation de pasteurisation ou de stérilisation.

Ce lait conserve toutes ces qualités d'aliment vivant, toutes ses vitamines et toutes ses facultés digestives.

La grande difficulté consiste dans l'obtention de ce lait propre et dans sa conservation à l'état où il se trouve au sortir de la mamelle.

Nous savons les efforis qui sont tentés par les Offices Agricoles,les Sociétés de puériculture, les Sociétés d'Agriculture pour parfaire l'éducation des vachers et obtenir des laits propres. Déjà des étables de premier choix ont obtenu d'heureux résultats. Ce problème se trouvera résolu et amélioré par une éducation longue, mais certaine, d'un personnel déjà mieux rémunéré, plus considéré et qui ne peut que continuer à s'améliorer.

Le mode de conservation du lait a fait l'objet d'une étude approfondie de la part du Comité d'Elevage de l'Office Agricole de Seineet-Oise, qui est arrivé à ces conclusions :

Pour maintenir le lait dans l'état le plus voisin possible de sa production, il faut le traiter par le froid aussitôt après la traite, le manipuler le moins souvent possible, éviter autant que possible les souillures atmosphériques.

Pratiquement, par un dispositif ingénieux, ce Comité semble avoir résolu la question.

Pour éviter la présence du pot à lait dans la vacherie, la machine à glace, à poste fixe ou sur chariot mobile, est placé à proximité de la vacherie et n'en est séparé que par une porte de préférence à ressort, afin que les vachers puissent aisément la forcer et qu'elle soit toujours fermée.

Après la traite de chaque vache, le vacher apporte son lait dans cette petite laiterie et le verse directement sur le réfrigérant, sans emprunter le pot à lait de vacherie. 
L'appareil comprend un réfrigérant à double circulation, d'eau courante à la partie supérieure, d'eau froide ou saumure à la partie inférieure(fig. 1). A sa base, un réservoir contenant une vingtainè de litres permet aux vachers de verser leur lait sans se préoccuper du pot devant recevoir définitivement le lait refroidi, et de remplir d'un seul coup ces derniers quand le réservoir est plein.

Le tout est surmonté d'un manteau métallique qui, gràce à un joint hydraulique, empêche tout passage d'air et, par conséquent, toute condensation de l'humidité de l'air et de ses poussières sur la paroi troide que torme le lait.

Un dispositif spécial, placé sous le réfrigérant, oblige l'air qui doit arriver sous le manteau à passer dans un eylindre parcouru lui-même par les tubes d'eau froide ou de saumure à leur sortie de la machine à glace. La condensation partielle de cet air s'opère alors, entraînañt dans tous les cas le dépôt des poussières atmosphériques, si bien que les cheminées d'air à l'intérieur du manteau ne laissent passer que de l'air relativement sec et pur.

Pour faciliter la tâche de l'agriculteur, il a été fait choix d'une ma. chine à glace particulièrement simple, complètement fermée,et ne nécessitant que le graissage des paliers. Il s'agit en la circonstance de la machine Singrün particulièrement favorable à cette combinaison (fig. 2).

Les calculs ont permis d'utiliser cette machine pour einquante vaches; le temps nécessaire à la traite permet la réfrigération du lait produit de la température du corps à celle de $6^{\circ}$ environ,

A cette température, le lait se comporte très bien, et lorsqu'il est livré en pots n'élève en douze heures sa température que de $2^{\circ}$ à $3^{\circ}$ environ.

Nons rendrons compte par la suite à nos leeteurs des résultats détaillés obtenus; des expériences en cours donnant tous détails appropriés et vérifiés feront l'objet d'un rapport général que nous publierons en temps.

Dès maintenant, il peut être affirmé que le but pratique est atteint et que la dépense entraînée par cette préparation, à peu près analogue à celle de la pasteurisation, permet de livrer dans la pratique un lait propre et conservant ses qualités primitives.

\title{
LES GONDITIONS DUNE BONNE ETABLE,
}

\author{
par HENRY BARTMANN,
}

Ingénieur-agronome.

Sous notre climat, la température n'est pas suffisamment élevée et régulière pour qu'il soit possible, en général de laisser les vaches laitières continuellement à la pâture. Il faut, pendant les $2 / 3$ de 